\title{
Debates del exilio francés de Nueva York durante la ocupación nazi. Su recepción en la Revista de los intelectuales europeos en América (Buenos Aires, 1942-1946)
}

Miranda Lida ${ }^{1}$

Universidad de San Andrés - Consejo Nacional de Investigaciones Científicas y Técnicas (Conicet), Argentina.

Correo electrónico: mlida@udesa.edu.ar

\section{Resumen}

En 1942 comenzó a publicarse la Revista de los intelectuales europeos en América (RIEA), una revista cultural que tuvo un fuerte compromiso con el antifascismo y con la resistencia francesa. La situaremos en el mapa de las revistas culturales antifascistas y a la vez daremos cuenta de sus redes con el exilio intelectual francés en las Américas. Este contexto permite explicar el modo en que la revista cobijó los debates que atravesaron el campo de los exiliados franceses del exilio neoyorquino en torno de la resistencia encabezada por de Gaulle, porque si bien se trata de una revista que intentaba transmitir una imagen compacta del antifascismo, no pudo eludir las polémicas que se multiplicaron a medida que avanzaba la guerra. Nos detendremos en el debate que sostuvieron Antoine de Saint-Exupéry y Jacques Maritain, dos nombres de peso en el exilio intelectual de la Segunda Guerra Mundial. Iluminar los debates que se dieron en el seno de la comunidad del exilio francés en las Américas y el modo en que hallaron eco en la Argentina, puede no sólo aportar nuevas miradas a temas que ya tienen una cierta presencia en la historiografía, sino además ayudar a pensar cómo circulaban y se recibían las ideas.

1 Agradezco a Fernando Devoto, Diego Mauro, José Zanca e Ignacio López su lectura y sugerencias a una versión preliminar de este trabajo. Agradezco además los aportes de los evaluadores anónimos del Boletín. 
Debates in French exile in New York during the Nazi occupation. Its reception in the Revista de los intelectuales europeos en América (Buenos Aires, 1942-1946)

\begin{abstract}
The Revista de los intelectuales europeos en América (RIEA), a cultural magazine with a strong commitment to anti-fascism and the French Resistance, was born on 1942. We situate it on the map of anti-fascist cultural magazines and at the same time we give an account of its networks with the French intellectual exile in the Americas. This context makes possible to explain the way in which the magazine sheltered the debates that ran through the French exile camp in New York about the resistance led by de Gaulle, because although it was a magazine that tried to convey a compact image of anti-fascism, it could not avoid the polemics that multiplied as the war progressed. We will focus on the debate between Antoine de Saint-Exupéry and Jacques Maritain, two leading names in intellectual exile during the Second World War. Illuminating the debates that took place within the French exile community in the Americas and the way in which they were echoed in Argentina can not only shed new light on issues that already have a certain presence in the historiography, but also help us to think about how ideas circulated and were received.
\end{abstract}

Keywords: Antifascism, Cultural journals, Argentina, Second World War, Jacques Maritain.

\title{
Introducción
}

En 1942, comenzó a publicarse en Buenos Aires la Revista de los intelectuales europeos en América (en adelante, RIEA), una revista cultural que tuvo un fuerte compromiso político con el antifascismo y, en especial, con la resistencia y el exilio franceses. Para ello tendió vínculos desde sus primeros números con diferentes escenarios continentales, sobre todo, allí donde hubiera intelectuales antifascistas como exiliados o refugiados provenientes de diferentes países europeos y que hubieran huido de la Francia ocupada por el nazismo. Así, en RIEA publicaron las principales plumas del exilio intelectual francés, fuertemente críticas tanto del régimen nazi como del mariscal Pétain a la vez, ya fuere que residieran en Gran Bretaña o bien en los Estados Unidos o en diferentes países latinoamericanos. Se trata de una revista que no ha sido incluida en los estudios del antifascismo, un campo de estudios fuertemente consolidado en la Argentina y en otros países, donde se ha puesto más énfasis, en general, en las organizaciones políticas y su impacto en la política argentina, así como también en las principales orientaciones ideológicas (Bisso, 2016; Bisso, 2005; Pasolini, 2013); se ha abordado también la relación entre cultura, política y antifascismo en distintos contextos intelectuales y estéticos (Saítta, 2005; Devés, 2016; Devés, 2016-2017; Guzmán, 2012). Existen, de todas formas, trabajos sobre importantes revistas antifascistas publicadas en la Argentina, varias de ellas vinculadas a redes de intelectuales comunistas, tanto 
en Argentina como en América Latina, así como también a otros movimientos liberal-socialistas (Bisso, 2009; Bisso, 2019; Celentano, 2006; Bertúa, 2015). Los estudios sobre revistas culturales se han mostrado muy productivos para iluminar distintos aspectos de la historia intelectual y política a través de las redes, las sociabilidades y los intercambios que gracias a ellas se tejen y consolidan, es decir, que son un objeto de estudio en sí mismo que ha venido ganando mucho terreno en la historia intelectual, política y cultural (Pita González, 2016; Mc Quade, 1992; Pasternac, 2002; Peirano Basso, 2001; Beigel, 2006; Granados y Rivera Mir, 2018).

En este trabajo procuraremos presentar, caracterizar y situar la RIEA en el mapa general de las revistas culturales antifascistas editadas en la Argentina, identificar su grupo editor, definir su perfil, sus especificidades y los motivos por los cuales consideramos que se trata de una publicación que merece un estudio específico. Nos concentraremos en prestar atención a sus redes transnacionales, que se nutrieron tanto del exilio republicano español, con el que tenía proximidad y de ahí la importante cantidad de plumas españolas que colaboraron en sus páginas- como del exilio intelectual francés provocado por la ocupación nazi. Así,los contactos transnacionales ocuparon un papel central en la vida de esta revista que, en general, dialogaba poco con el contexto político argentino o su escena literaria o intelectual, a diferencia de buena parte de las publicaciones y agrupaciones antifascistas de este período. En líneas generales podemos situar esta revista en el antifascismo no comunista (García, H., Yusta, M., Tabet, X. y Clímaco, C., 2016; Seidman, M., 2017) donde, además, se destacará el componente étnico puesto que se trata de una revista que construyó sus redes y contactos con el exilio francés en las Américas que, desde Estados Unidos hasta Buenos Aires, condenó el régimen de Vichy. ${ }^{2}$ Ahora bien, aún en este preciso contexto, nos interesa también pensar el modo en que la revista participó de los debates que atravesaron el campo de los exiliados franceses del exilio neoyorquino y sus posicionamientos, no siempre homogéneos, frente a la causa de la resistencia encabezada por de Gaulle, porque si bien se trata de una revista que, como veremos, intentaba transmitir una imagen compacta del antifascismo y del exilio francés, no pudo eludir las polémicas que se multiplicaron a medida que avanzaba la guerra y crecían las expectativas por la victoria aliada. Más precisamente, nos detendremos en el debate que sostuvieron Antoine de Saint-Exupéry y Jacques Maritain, dos nombres de peso en el exilio intelectual francés de la Segunda Guerra Mundial, que giró en torno del problema de la posibilidad (o no) de reconciliación de los intelectuales del exilio con los que se mantuvieron bajo el régimen de Vichy.

Se trata de debates que se dieron en un contexto en el que todavía no estaba definido el desenlace de la guerra y, por consiguiente, las posiciones de los franceses en el exilio todavía admitían alternativas que iban desde la condena lisa y llana del régimen de Vichy, hasta posiciones algo más indulgentes. Por contraste, luego de la liberación de París en agosto de 1944, a la par del proceso de "depuración" que se tradujo en las purgas masivas de colaboracionistas, habría menos lugar

2 Ricardo Pasolini, por ejemplo, subrayó el componente étnico en distintas agrupaciones y publicaciones antifascistas argentinas (Pasolini, 2006). 
para la indulgencia, pero no desaparecería del todo. La historiografía ha producido intensos debates en torno de Vichy, donde se ha puesto el foco en cuestiones tales como si el régimen del mariscal Pétain fue un simple "títere" al servicio del nazismo o bien tuvo una agenda propia que podía incluso ir más allá de la del propio Hitler en sus aristas represivas. También se ha discutido si la firma del armisticio en junio de 1940 fue solamente una estrategia defensiva, vale decir, un "escudo" frente al invasor, o incluso una imposición de éste o, más bien, este argumento del "escudo" fue sólo una argucia ex post de los colaboracionistas para procurar su exculpación, ocultando así las auténticas simpatías que habían tenido por el nazismo (Paxton, 1972; Aron, 1954). En este sentido, iluminar los debates que se dieron en el seno de la comunidad del exilio en las Américas -incluso desde antes de la liberación de París- y el modo en que hallaron eco en la Argentina a través de RIEA, puede no sólo aportar nuevas miradas a debates que ya tienen una cierta presencia en la historiografía (Reggiani, 2010), sino además ayudar a pensar cómo circulaban y se recibían esos debates, en especial, en una revista que estaba estrechamente vinculada al antifascismo y al exilio francés como fue RIEA. Si bien no fue una revista central en el antifascismo argentino, se involucró de lleno en los debates del exilio francés y en este sentido su aporte es iluminador para pensar la complejidad del campo antifascista.

\section{Presentación de RIEA, su grupo editor, su perfil y su contexto}

El grupo editor de RIEA estuvo muy estrechamente vinculado a otros movimientos antifascistas y de solidaridad con el exilio republicano español que se desarrollaron en Argentina desde la segunda mitad de la década de 1930. En especial, salta a la vista la proximidad con Acción Argentina, principal agrupación antifascista, de composición liberal socialista, que se conformó a partir de 1940 (Bisso, 2007). Ahora bien, a pesar de los estrechos contactos que varios de los miembros del grupo editor sostuvieron con esta asociación, la revista se mantuvo apartada de los debates propios de la política argentina que se desarrollaban en el antifascismo, así, por ejemplo, omitió cualquier tipo de intervención pública en torno de cuestiones centrales de ese período (fraude electoral, corrupción, entre otras). La única mención a la coyuntura local salió a la luz en ocasión del terremoto de San Juan de enero de 1944 que, según declaró, tuvo fuerte repercusión internacional; en esta clave, la revista sacó una declaración en agradecimiento de la ayuda humanitaria internacional recibida por la Argentina. Significativamente, hizo cualquier omisión a la labor desempeñada por el secretario de Trabajo y Previsión Juan D. Perón, de amplia labor ante la catástrofe (Healey, 2012) y, por contraste, elogió las palabras del presidente de facto Pedro Ramírez y de la Iglesia Católica, lo cual es sintomático del perfil y la orientación del grupo editor de RIEA. ${ }^{3}$

Entre los nombres que lo compusieron se destacan conspicuas figuras provenientes de elites sociales, intelectuales y políticas, vinculadas al radicalismo 
antipersonalista o el partido socialista independiente: Adolfo Bioy (que presidía la Sociedad Rural Argentina), Rafael Bullrich (exdecano de la Facultad de Medicina, UBA), José María Cantilo (el exministro de Relaciones Exteriores durante el gobierno de Ortiz), Federico Pinedo (exministro de Hacienda) y Ricardo Levene (historiador). ${ }^{4}$ También le brindó su aval el expresidente radical Marcelo T. de Alvear, que formó parte de Acción Argentina igualmente. ${ }^{5}$ La revista reflejó y se nutrió de la fuerte matriz francófila que todavía prevalecía entre diversos sectores de las elites intelectuales, sociales y políticas. (Rolland, 1995). Adolfo Bioy fue una figura clave en esta publicación que en todo sentido llevó su impronta, puesto que desde 1921 Bioy había alentado, fundado y dirigido el Instituto de la Universidad de París en Buenos Aires (con la que también colaboraron otros miembros del comité editorial de RIEA) que, de manera similar a otras instituciones establecidas para agilizar la diplomacia cultural en este período (así, por ejemplo, la Institución Cultural Española de Buenos Aires), se concentró en promover el intercambio científico y cultural entre Francia y la Argentina a través de la promoción de la ciencia y de la intelectualidad francesa en el país. Para ello se fijó una agenda de visitas regulares de científicos provenientes en general de la Sorbonne y del Collège de France -a los invitados se les costeaba un viaje para dictar cursos y conferencias en la Universidad de Buenos Aires, entre otras-. El Instituto de la Universidad de París contó con fondos públicos provenientes del Estado argentino y, además, con reconocimiento oficial por parte del gobierno francés (Buchbinder, 2017). ${ }^{6}$ Por su origen francés (el apellido materno de Adolfo Bioy era Domecq) y por sus fuertes contactos con las elites políticas argentinas de la década de 1930, llamada "infame", así como también con las elites intelectuales francesas o con las que sostuvo relación estrecha desde antes de que se produjera la ocupación nazi, la figura de Adolfo Bioy en este grupo es de relieve, dado que permitió enlazar esta revista con la actividad desarrollada por el Instituto de la Universidad de París, que cumplió 20 años justo en 1942, cuando ya no podía ejercer sus funciones. Así, en tiempos de guerra, el Instituto procuró mantener su vigencia gracias a RIEA. ${ }^{7}$ El proyecto de la revista no puede, pues, entenderse al margen de la intensa gestión de diplomacia cultural que desarrolló Bioy al frente de dicho instituto francoargentino, cuya labor se vio obstaculizada en 1940. Eran escasos y muy raros los avisos publicitarios que ocuparían sus páginas de tal modo que bien puede deducirse que la revista contaba con recursos propios.

Si la figura de Adolfo Bioy es decisiva para entender algunos rasgos de la publicación, no menos significativo es describir su perfil, formato y aspecto general. Se trató de una revista de formato libro de regularidad mensual, en entregas de

4 Completan la nómina Pablo Calatayud, Agustín Matienzo, José Padilla, Mariano Drago, Enrique García Mérou, Martín Noel.

5 Acerca de la compleja relación del expresidente radical con el antifascismo véase Losada, L. (2016: pp. 255-270).

6 Como muestra Buchbinder, dicho instituto se financió con fondos franceses y con aportes de las universidades argentinas. También contó con subsidios del gobierno nacional. Al respecto, véase "Instituto de la Universidad de París. Subsidio", Archivo del Patrimonio Legislativo (Argentina), disponible online en https://docs.google.com/gview?url=http://apym.hcdn.gob.ar/uploads/expedientes/pdf/1267-p-1934. pdf\&embedded=true, expediente 1267-P-1934, consultado en julio de 2020.

7 Bioy, A. (mayo 1942). La obra del Instituto de la Universidad de París en Buenos Aires, RIEA, (4), pp. 291-292. 
alrededor de cien páginas, con textos relativamente cortos, que rara vez incorporaba ilustraciones; los textos en ocasiones eran originales, pero no siempre era así, porque la revista reproducía publicaciones antifascistas de otras latitudes (en especial, de Estados Unidos, Canadá y México), e incluso transcribía textos clásicos que se vinculaban con el propósito de la revista, es decir, evocar el legado de la Revolución francesa, mancillado por la ocupación nazi y reforzar el sentimiento antifascista. No faltarían, así, extractos de pensadores liberales franceses como Benjamin Constant y Madame de Staël, e incluso de tradicionalistas como Joseph de Maistre (a quien se recuperaría en RIEA, así como en la argentina Sur, como autor antibonapartista, antes que reaccionario, en un momento en que la comparación entre Hitler y Napoleón era muy habitual a la luz de la operación Barbarroja) ${ }^{8}$; también se publicarían, entre los clásicos, autores no franceses como León Tolstoi, por su evocación en La guerra y la paz de la campaña contra Napoleón. ${ }^{9}$ El subtítulo de la revista era "Selecciones - testimonios - comentarios", de tal modo que puede advertirse que seguía el modelo de los digests norteamericanos ${ }^{10}$, con artículos abreviados y síntesis de debates de trabajos publicados en una amplia gama de publicaciones internacionales, con la expectativa de llegar a un público lo más amplio posible; los artículos eran presentados sin jerarquizar ni ordenar en secciones y apenas quedaban unas pocas páginas para breves reseñas de libros u otras noticias o comentarios. El perfil de la revista estaba dado en todos los casos por el criterio con el que se hacía la selección de los contenidos que, como se indicó, distaban de ser completamente originales en cada tirada, criterio que llevaba explícito un fuerte compromiso con los intelectuales antifascistas y, en especial, franceses. La revista publicaba desde fragmentos de libros de reciente aparición hasta reseñas, así como también reeditaba artículos publicados previamente en algunas revistas a las que prestaba especial atención, provenientes en general de la escena francófila en diferentes países americanos. Entre las revistas citadas con más frecuencia se destacan varias vinculadas al humanismo cristiano (Esprit, La Nouvelle Relève y Commonwealth); otras revistas citadas formaban parte de una red de publicaciones dirigidas a difundir y reforzar los valores asociados al panamericanismo (entre ellas, América y Mundo libre, de México o Nueva democracia de Nueva York). En su primer número, la publicación se presentó como puente entre la cultura occidental, diezmada por el nazismo, y América, con especial preocupación por la intelectualidad francesa, entendida como faro de la república de las letras amenazada:

El conflicto mundial ha disuelto la "república de las letras", aquella federación de intelectuales libres [...] El espíritu es la primera gran víctima de la guerra. La civilización de occidente sufre la peor crisis de la historia [...] Los intelectuales americanos tienen la grave responsabilidad de levantar firme [...] la antorcha del pensamiento occidental. No están solos, sin embargo: numerosos intelectuales europeos que se han radicado entre nosotros permanecen fieles a su vocación. [...] nos proponemos colaborar al

8 de Maistre, J. (marzo 1942). La derrota de Napoleón en Rusia, RIEA, (2), pp. 56-57; de Maistre, J. (febrero 1942). La campagne de Russie, Lettres françaises, (2), pp. 51-53.

9 Tolstoi, L. (abril 1943). La guerra y la paz, RIEA, (15), pp. 180-185.

10 Coincidió con el momento de expansión en América Latina del Reader's Digest. Véase en este sentido Ubelaker Andrade, L. (2019). 
restablecimiento del diálogo entre Europa y América. [...] ningún silencio nos afecta tanto como el de Francia [...] Mientras quedan apagadas las luces del espíritu en Francia, nos esforzaremos en mantener su influencia y su significado universales. ${ }^{11}$

La "república de las letras" que se evocaba tenía su corazón en una Francia que ya no era tal, debido a la ocupación y la partición del territorio, a la par que se conformaba el régimen de Vichy bajo el mariscal Pétain. El "luto por Francia" presente entre distintos grupos de inclinación antifascista (Bisso, 2005, pp. 84-90) se superponía al lamento por la cultura occidental. La revista, sin embargo, no se limitaba a reproducir plumas francesas, si bien ellas se contarán en importante proporción; como se adelantó, también publicaban intelectuales exiliados provenientes de la España republicana, junto a intelectuales provenientes de otros países bajo la ocupación nazi, ya fuere que se encuentren exiliados o refugiados en Estados Unidos, Gran Bretaña o diferentes países latinoamericanos. Así, por ejemplo, entre los exiliados republicanos españoles se destacan las colaboraciones de varios exiliados en México, entre ellos, el socialista Indalecio Prieto ${ }^{12}$, el escritor Enrique Díez Canedo ${ }^{13}$ y el diplomático e historiador Pedro Bosch Gimpera ${ }^{14}$, entre otros. También se siguieron de cerca algunas publicaciones de exiliados editadas en México, en especial Mundo Libre, revista de derecho internacional fundada por el diplomático Isidro Fabela que prestaba atención a diferentes cuestiones de índole internacional (Marín, M., 1964; Jorge, D., 2015), entre otras; las decisiones de guerra de los Aliados y sus diferentes tratativas, en la que colaboraron, también, exiliados huidos del nazismo como Eduard Benes -presidente de Checoslovaquia antes de la ocupación de los Sudetes y exiliado en Inglaterra-, quien resultó bastante asiduo colaborador en RIEA donde publicó un fuerte artículo bajo el elocuente título de "Con el nazismo, ningún acuerdo". ${ }^{15}$ Entre los exiliados republicanos se destacan las colaboraciones de Augusto Pi Suñer, Jacinto Grau, Claudio Sánchez Albornoz y el presidente republicano Niceto Alcalá Zamora. ${ }^{16}$ Otros colaboradores provenientes del antifascismo europeo no francés fueron el demócrata cristiano italiano Luigi Sturzo ${ }^{17}$ (con colaboraciones asiduas en diversas publicaciones antifascistas), el conde Carlo Sforza, que leía Maquiavelo en clave mazziniania y antifascista ${ }^{18}$, junto a Stefan Zweig, Maurice Maeterlinck, entre

11 S/firma. (febrero 1942). Presentación al lector, Revista mensual de los intelectuales europeos en América, (1), pp. 1-2. (Los destacados son nuestros.)

12 Prieto, I. (agosto 1942). Diez gotas de tinta, RIEA, (7), pp. 2-6.

13 Díez Canedo, E. (abril 1942). Florencio Sánchez y su obra, RIEA, (3), pp. 256-261.

14 Bosch Gimpera, P. (diciembre 1942). Por la eficacia de nuestra lucha, (11), pp. 411-413.

15 Benes, E. (mayo 1942). Con el nazismo, ningún acuerdo, RIEA, (4), p. 290 y Benes, E. (agosto 1942) La democracia. Su definición, origen, evolución y porvenir, RIEA, (7), pp. 15-22.

16 Pi Suñer, A. (julio 1942). La sabiduría del cuerpo, RIEA, pp. 540-545; Sánchez Albornoz, C. (julio de 1943). La mujer española hace 1000 años, RIEA, pp. 522-526; Alcalá Zamora, N. (abril 1942). Régimen de libertades y demoro de polémicas, RIEA, (3), pp. 194-197.

17 Además de Sturzo, RIEA tuvo conexiones con otras expresiones del catolicismo antifascista, a saber, el clero vasco, monseñor Miguel de Andrea, Joseph Ducatillon, Tristão de Athayde. Por ejemplo, seguía atentamente las ediciones vascas Ekin. Al respecto, véase Mauro, D. (2017); Zanca, J. (2013); Lida, M. (2013); Vicente, M. (2015).

18 Sforza, C. (diciembre 1942). El pensamiento vivo de Maquiavelo, RIEA, pp. 414-421. Para un cuadro general de la recepción de Maquiavelo en Argentina véase Losada, L. (2019). 
otros. ${ }^{19}$ Los intelectuales franceses en el exilio los abordaremos en el próximo apartado, dado que ocupan el grueso de sus páginas y el centro de los debates.

Por supuesto, no se trató de la única revista en los años de la Segunda Guerra Mundial que enarboló las banderas del antifascismo; hubo de hecho un número creciente de publicaciones, foros y expresiones de los intelectuales antifascistas en la Argentina que ya ha sido ampliamente estudiado, entre los que se destacó la AIAPE (Pasolini, 2015; Cane, 1997; Petra, 2017). En este contexto, pues, entre tantas publicaciones y foros antifascistas que aparecieron en esos años ¿cuál es la especificidad de RIEA y por qué tiene sentido que nos detengamos en ella? RIEA es algo más y algo menos, a la vez, que una revista antifascista. Es algo más, puesto que se trata básicamente de una revista cultural y literaria, aunque de divulgación, al estilo de los digests norteamericanos -como se señaló- donde se procuraba en la medida de lo posible eludir la confrontación ideológica, al menos la más frontal; tampoco se entraba en polémica con otras revistas, ya fueran ajenas al antifascismo, o bien pertenecientes a otras tradiciones ideológicas o políticas. Evitaba en este sentido el mero proselitismo; si bien enarbolaba la causa de la resistencia francesa y adhería de manera explícita al antifascismo y a Charles de Gaulle, no se trataba de un boletín militante destinado a incitar al lector a adherir a la causa gaullista, sino que más bien buscaba persuadirlo a través de los argumentos, en una clave espiritual antes que polémica, acerca de la superioridad moral y civilizatoria que suponía la defensa de dicha causa, frente a la barbarie y el oscurantismo nazi. Su aporte consistió, más bien, en proporcionarles a los intelectuales exiliados unas páginas amigas en donde publicar en un momento en que la vida intelectual parecía quedar en suspenso, en especial en Europa continental, bajo el dominio del Eje; se les dio una voz que a su vez procuraba tener alcance continental. De esta manera se mantendría el vínculo con los intelectuales franceses del exilio, vínculo que, una vez superada la coyuntura bélica, podría servir de base para recomponer la relación. Desde el comienzo se dio por descontado que el lector de RIEA era ya antifascista; no era necesario convencerlo de ello, sino que se buscaba más bien reafirmar sus convicciones en su adhesión al antifascismo en tanto que expresión de valores culturales y “espirituales”, más que políticos, de allí que se buscara amortiguar las polémicas en lugar de azuzarlas. A diferencia de otras revistas que alcanzaron protagonismo en el debate de ideas, e incluso en ocasiones polemizaron con publicaciones de tintes nacionalistas o católicas ${ }^{20}$, y por tanto tenían un alto perfil en el debate ideológico (Zanca, 2013; Lida, 2015), RIEA se mantuvo lejos de las candilejas, motivo por el cual, podemos quizás aventurar, permaneció mayormente en un segundo plano y quizás por eso quedó bastante olvidada en la memoria de esos años. ${ }^{21}$ Su función, al fin y

19 RIEA reflejaba un amplio arco de publicaciones antifascistas transnacionales de las que reproducía muchas veces artículos, entre ellas: América (revista literaria de México), Francia Libre (editada en Londres), la ampliamente conocida revista católica personalista francesa Esprit de Emmanuel Mounier, y varias revistas antifascistas, gaullistas o panamericanistas editadas en Nueva York, entre ellas Free World, Nueva Democracia, Commonwealth, La Voix de France.

20 En este sentido, por ejemplo, podemos recordar desde los años de la Guerra Civil española los debates intensos de Sur con revistas católicas como Criterio y, también, la relación que tejió con Orden Cristiano, impugnada sin embargo por otras publicaciones católicas, entre ellas, El Pueblo.

21 En efecto, no aparece registro de ella en Lafleur, H., Provenzano, S. y Alonso, F. (2006). 
al cabo, no era avivar el debate intelectual, sino mantener vivo el vínculo con los intelectuales franceses en el exilio, que había quedado en suspenso a raíz del exilio y la ocupación, y que había vuelto inútil y sinsentido la labor del Instituto de la Universidad de París en Buenos Aires dirigido por Bioy, y que sería decisivo para cualquier intento futuro de restablecer dicho instituto abocado a la diplomacia cultural francoargentina. En este sentido, pues, la especificidad de esta revista no puede ser comprendida por fuera de esta institución. ${ }^{22}$

En Buenos Aires circulaban otras revistas y publicaciones periódicas de carácter militante que abonaban la causa antifascista y gaullista a la vez, editadas incluso en lengua gala, para su circulación en la comunidad francoparlante de la Argentina: así, Pour la France Libre, editada por el Comité de Gaulle, con edición bilingüe, mayormente en español, editada en Buenos Aires por Albert Guérin, excombatiente de la Primera Guerra Mundial. Dicha publicación tejió contacto con el propio de Gaulle, hizo campañas de recaudación de fondos y ganó crecientes apoyos en la comunidad francesa en el país, a medida que avanzaba la guerra y mejoraba la posición aliada en el conflicto (Otero, 2012: 304-306; Pelosi, 1999; Bisso, 2007: 139-144). Otras publicaciones que sostenían la causa aliada y estaban a su vez comprometidas con la resistencia francesa y con de Gaulle fueron $\mathrm{La}$ voz de Francia /La Voix de France y La France Nouvelle, ambas en edición bilingüe, editadas en Buenos Aires. Con las publicaciones antifascistas no francófonas editada en Buenos Aires tuvo menos diálogo en general, así, por ejemplo, no tuvo mayor acercamiento con la "otra Alemania", la de los alemanes antifascistas de la Argentina (Friedmann, 2010).

Last but not least cabe poner de relieve en un renglón destacado la revista literaria Lettres Françaises que apareció bajo la forma de cuadernos trimestrales publicados por la editorial Sur, vale decir, con el respaldo financiero de Victoria Ocampo y la dirección de Roger Caillois, crítico literario francés exiliado de la Francia de Vichy que se instaló en la Argentina durante la Segunda Guerra Mundial bajo la protección de Victoria Ocampo (King, 1989). Lettres Françaises, que apareció en francés en octubre de 1941, apenas unos meses antes que RIEA, tuvo muchos puntos de contacto con ésta; de hecho, Roger Caillois colaboró en RIEA desde su primer número, como se verá enseguida. Editada por el grupo liderado por la fundadora de Sur, Lettres Françaises era, sobre todo, una revista literaria, con el mismo perfil, formato y diseño de Sur, donde se publicaban textos originales de plumas tanto francesas como argentinas -en este último caso, se los traducía al francés- que en su mayor parte ya habían sido asiduos colaboradores en Sur, aunque también se reproducían fragmentos y antologías de textos y ensayos, donde no faltaron cuestionamientos a intelectuales y revistas francesas publicadas en la Francia de la ocupación. Como sea, Lettres francaises es sobre todo una revista literaria que priorizó la lengua francesa y dejó escaso espacio a plumas no francoparlantes provenientes del arco antifascista europeo. En ese sentido, la diferencia sustancial entre ambas es que RIEA, editada en español y de fuerte impronta americanista, dialogaba con escritores exiliados y refugiados 
del nazismo provenientes de diferentes latitudes, sin poner como requisito el uso de la lengua francesa, lo cual le permitió incorporar y ampliar el arco de los colaboradores de la revista -en comparación con la que dirigía Caillois- aunque, por su formato ajustado, limitado por lo general a textos breves, se tendía muchas veces (aunque no siempre) a reproducir síntesis de artículos ya publicados en otros lados, en lugar de generar aportes novedosos. Ello convertía a RIEA más en una caja de resonancia de debates que circulaban en otros espacios que en una auténtica cantera de ideas originales, puesto que su función era, sobre todo, mantener el vínculo con los autores que habían sido antes de la ocupación alemana los interlocutores habituales del Instituto de la Universidad de París en Buenos Aires. Sin embargo, como se verá a continuación, sería simplista reducirla a una mera repetidora de ideas producidas en otros lados.

\section{Francia fuera de Francia. RIEA como caja de resonancia del exilio francés en Nueva York}

El lugar de Francia en la revista fue, como se ha adelantado, central; así, los debates que atravesaron a los intelectuales franceses durante la guerra tendrán en RIEA fuerte eco. Ocuparon un lugar en sus páginas un arco variado de intelectuales de diferentes orígenes políticos e ideológicos, desde católicos hasta comunistas, muchos de ellos en el exilio en Estados Unidos, Inglaterra y América Latina. No caben dudas del posicionamiento fuertemente crítico de la revista para con el régimen de Vichy y, a su vez, el entusiasmo creciente que despertaba la figura de Charles de Gaulle, que encabezaba desde Londres la resistencia francesa. Así,por ejemplo, se siguió de cerca la creación del comité francés de liberación nacional, encabezado por De Gaulle, del cual se reprodujeron algunos fragmentos de sus discursos. ${ }^{23}$ Pero no se puede pasar por alto que cuando se trataba de despertar la conciencia de los franceses contra el invasor, RIEA recuperaría y pondría en valor la voz de Georges Bernanos, intelectual católico de tendencia tradicionalista-que había terminado por adoptar una postura crítica con respecto al levantamiento franquista en España si bien lo apoyó en un primer momento- que apeló a la unidad nacional ("no miréis ni a derecha ni a izquierda", recalcó) para poder conformar un frente común ante el invasor alemán, en un discurso caracterizado como conmovedor y vibrante por los editores de RIEA. ${ }^{24}$

No obstante ello, las polémicas suscitadas por el posicionamiento de los franceses frente a la ocupación no tardaron en salir a la luz. Las polémicas que se vieron reflejadas en RIEA no tuvieron que ver con vacilaciones a la hora de tomar posición ante la invasión alemana, puesto que prácticamente todas las plumas francesas que escribieron en ella pertenecían al campo del exilio y tenían libertad para escribir, a diferencia de los que permanecieron bajo tierra gala sometidos a

23 S/a. (septiembre 1943). El general De Gaulle expone los ideales del pueblo francés, RIEA, (20), pp. 142-143.

24 Bernanos, G. (febrero 1943). Mensaje a los franceses, RIEA, (13), pp. 5-6. 
regímenes opresivos o censura; más bien tuvieron que ver con discusiones entre los exiliados en la medida en que muchos de ellos comenzaron a involucrarse de un modo u otro en la causa de la Francia libre, como muchos movimientos antifascistas lo harían también. Ahora bien, en el caso de los intelectuales franceses la cuestión más espinosa fue qué actitud tomar frente a aquellos hombres de letras, incluso prestigiosos, que permanecieron en tierra gala sin alzar su voz contra la opresión, puesto que no faltaron acusaciones por su silencio frente al régimen nazi o de una velada complicidad, a pesar de que no se podían ignorar las condiciones de censura bajo las cuales vivían. En este sentido cabe poner de relieve que Roger Caillois, uno de los más renombrados exiliados franceses en la Argentina, se encargó desde el primer número de RIEA de sentar posición en esta espinosa cuestión que atravesaba a los intelectuales franceses a los dos lados del Atlántico. Ahora bien, el gesto que rescató RIEA es que Caillois fue indulgente con sus compatriotas que permanecían en tierras francesas, puso énfasis en que no se podían ignorar las condiciones de represión en las que se vivía y, por tanto, no debía juzgárselos por su silencio o convertirlos en objeto de maledicencias o suspicacias. Más aún, agregaba, era necesario suavizar las acusaciones y ser comprensivos con los compatriotas:

\footnotetext{
Es necesario que los escritores que gozan de una entera libertad para expresarse y se ven constantemente tentados de abusar de ella por influencia del medio en que viven [...] se moderen haciéndose así solidarios de los que se ven obligados a guardar en Francia un semi-silencio. Cuando unos están amordazados es justo que los otros se cuiden voluntariamente de un exceso de licencia [...] este respeto continuo hacia los escritores que han permanecido en Francia no entraña ninguna cómoda prudencia, no aconseja ninguna neutralidad, ningún silencio. ¿Quién pretende que los intelectuales de allá son neutrales? [...] se necesitaría por lo menos que se les dejara expresar.
}

Luego de clamar indulgencia, Caillois agregaba, además, la necesidad de fortalecer la solidaridad entre unos y otros, tanto entre los exiliados como entre los que optaron por permanecer en Francia en 1940, dándole a los exiliados una autoridad reconocida para hablar en nombre de todos. Concluía:

\begin{abstract}
He aquí el deber de los escritores franceses en el extranjero: querer ser los intérpretes atentos de sus camaradas que se ven reducidos a expresarse cuchicheando. Es falso que no deban formular ningún juicio, [...] La fidelidad [...] obliga por el contrario a cada uno a comprometerse y a tomar partido. [...] Así podría nacer una especie de solidaridad orgánica [...] Hoy día los escritores franceses residentes en su país o en el extranjero necesitan unos de otros. Los que allí no pueden hablar ni actuar delegan en los ausentes [...] Nosotros que somos libres debemos sentirnos ligados por ese lazo invisible. ${ }^{25}$
\end{abstract}

La autorizada voz de Caillois en tanto que exiliado, así como también en tanto que editor de la principal revista editada en Buenos Aires para los intelectuales franceses en el exilio, fue hecha suya por los editores de RIEA. Por su parte, mientras tanto, André Gide, nombre de peso en la intelectualidad francesa, si bien cuestionado por la izquierda comunista a partir de 1936 por su libro Regreso de la URSS

25 Caillois, R. (febrero 1942). Deberes y privilegios de los escritores franceses en el extranjero, RIEA, (1) pp. 82-83. 
en el que denunció las consecuencias sociales de los planes quinquenales estalinistas, confirmó pocos números después, también en un artículo relevado en RIEA, que los intelectuales que permanecieron en Francia se encontraban literalmente amordazados por la censura, por lo cual apelaban al recurso de escribir en clave, o bien utilizaban referencias anodinas a autores clásicos en las letras francesas que escondían mensajes velados, estrategias que eran comunes a otros escritores bajo situaciones similares, entre ellos, François Mauriac o Edouard Herriot. ${ }^{26}$ En este contexto, la revista mostró preocupación por la puesta en vigencia de la lista Otto, confeccionada, según RIEA, "con poco discernimiento y poco sentido de la jerarquía intelectual”, a través de la cual el régimen nazi de ocupación impuso la censura y la prohibición de libros en las tierras francesas bajo su jurisdicción, con más de mil títulos, muchos de ellos de autores judíos, comunistas o, en general, de izquierda, que solo podían de ahí en adelante ser leídos en la clandestinidad, con los riesgos que ello implicaba. ${ }^{27}$

Así, pues, la relación entre los intelectuales franceses, bajo dictadura o democracia, a los dos lados del Atlántico planteó desde un comienzo fuertes desafíos para una revista como RIEA. El llamamiento ecuménico a todos los intelectuales franceses que lanzó Caillois en su primer número a fin de tender lazos "invisibles" que expresaran una fuerte "solidaridad orgánica" entre ellos marcó la pauta de la revista que no vacilará en seguir de cerca a los principales núcleos, redes y referentes del exilio intelectual francés, con el propósito de aproximarlos y mitigar sus diferencias o eventuales discordias. A la vez, sin embargo, no por ello dejaría de prestar atención a quienes permanecieron en tierras francesas, con posiciones públicas de fuerte críticas al régimen de Vichy, en especial François Mauriac, que mantuvo en un principio una posición conciliadora con la ocupación y conservó su plaza en la Académie Francaise donde coincidió con el integrista Charles Maurras, fundador de la Action Française quien escribió "París [...] ha sobrevivido a otras vergüenzas", o quien, como el periodista Henri de Kerillis, se volcó al gaullismo aun cuando provenía del nacionalismo y denunció como colaboracionista al escritor Alphonse de Chateaubriant en sendas colaboraciones exclusivas para RIEA. ${ }^{28}$

Ahora bien, entre los interlocutores más importantes de RIEA se destacó el grupo de exiliados franceses que se estableció en Nueva York, en cuyo seno estuvieron el filósofo Jacques Maritain y el escritor Jules Romains (aunque este último terminó luego por establecerse en México), exiliados desde la primera hora de la ocupación nazi de Francia, grupo que fundó la Maison du Livre Français, una editorial que se convirtió en la principal casa de los intelectuales franceses en el exilio y se mantuvo en plena actividad durante toda la Segunda Guerra Mundial. Sus libros circulaban rápidamente y eran reseñados de inmediato en RIEA en Buenos Aires. Por supuesto, no eran las únicas novedades editoriales que se

26 Gide, A. (junio 1942). Entrevistas imaginarias (publicadas originalmente en Le Figaro, de Lyon), RIEA, (5), pp. 394-395.

27 El listado incluyó a Freud, Chesterton, Duhamel, Maurois, Blum, Zweig, entre otros. S/firma. (julio 1942). La lista Otto, RIEA, (6), p. 539.

28 Mauriac, F. (agosto 1942). París, 1942, RIEA, (7), pp. 79-80; de Kerillis, H. (agosto 1942). Cerebros torcidos, inteligencias extraviadas, RIEA, (7), pp. 79-80. Para un contexto general, véase Goetschel y Loyer (2011); Burrin (1995: pp. 336-338). 
reseñaban en RIEA: así, por ejemplo, se seguían de cerca las publicadas por las casas editoriales estrechamente vinculadas al exilio republicano español, en especial Losada y Sudamericana, así como también se les prestaba mucha atención a diversas obras de actualidad (testimonios, ensayos, crónicas) que daban cuenta de la situación en diferentes frentes bélicos, que solían aparecer publicadas en la editorial Claridad donde vieron la luz testimonios de la vida en los campos nazis de concentración ${ }^{29}$; o también distintos ensayos sobre temas de actualidad que podían incluir reflexiones sobre el papel de la Unión Soviética en la guerra ${ }^{30}$; o bien sobre la resistencia y su rol en el desenlace de la segunda guerra mundial ${ }^{31}$; e incluso abrir la reflexión acerca del nuevo mapa mundial que se avecinaría una vez que la guerra llegara a su fin y, en especial, acerca del lugar que les tocaría en él a China, la India, entre otros países, desde una mirada que buscaba salirse del eurocentrismo ${ }^{32}$.

No obstante, en todo momento los intelectuales franceses conservaron un sitio privilegiado en RIEA, así como también en los debates y polémicas que los atravesaron desde los tramos finales de la guerra. El lugar más conspicuo estuvo ocupado por los exiliados franceses en Nueva York, entre ellos, el ya mencionado Maritain y el historiador de arte Henri Focillon, por mencionar dos nombres que no podían resultar indiferentes en la Argentina, dado que ambos habían visitado el país en el transcurso de los años treinta -Maritain había viajado en ocasión del Congreso del PEN Club en 1936 cuando participó de un sonado debate de fuerte impacto en el catolicismo argentino y Focillon por su parte en 1937 por invitación del Instituto de la Universidad de París, bajo la dirección de Bioy-. Estos mismos nombres encabezaron en 1942 la fundación de una "universidad del exilio" en Nueva York, junto a Claude Lévi Strauss, entre otros, empresa que contó con el apoyo de la Fundación Rockefeller para establecer l'École Libre des Hautes Études, asociada a la New School of Social Research, cuyo rol en la acogida de científicos refugiados provenientes de Europa central, muchos de ellos judíos, es bien conocido (Krohn, 2017; Krohn, 1993). Este proyecto, que fue impulsado en primer lugar por los emigrados franceses, con el apoyo del prestigioso científico Jean Perrin, premio Nobel de Ciencias, tuvo diálogo directo con de Gaulle, que lo apoyó ampliamente con la idea de conformar un centro de investigación y de vida intelectual que se reivindicaba como la "verdadera" ciencia francesa, sin ir en desmedro de atraer en su seno a otros intelectuales y científicos no franceses que se sintieran atraídos por el proyecto, como fue el caso del filósofo Alexandre Koyré y el lingüista Roman Jakobson, ambos rusos y exiliados en Estados Unidos, que además brindaron su apoyo a de Gaulle en la lucha contra el nazismo en Europa (Chaubet y Loyer, 2000).

Se trata, pues, de la principal institución científica francesa en el exilio, primera en su tipo que no tardaría en verse reflejada en las páginas de RIEA. Dada la

29 Encuesta ¿Qué hacer con Alemania?, RIEA, 40 (junio 1945), pp. 236-244.

30 Johnson, H. (junio 1942). El poder soviético, RIEA, (5), pp. 386-393.

31 Barres, P. (septiembre-octubre 1944). La Cruz de Lorena, RIEA, 32-33 Número especial por la liberación, pp. 78-91.

32 Shridharani, K. (mayo 1944). Los amigos del lejano Oriente, RIEA, (28), pp. 231-241. 
amplia trayectoria de Bioy en el Instituto de la Universidad de París en Buenos Aires, y su relación de larga data con las elites universitarias francesa exiliadas en Nueva York, no es casual la centralidad que se le dio en la revista. A la par que reprodujo los discursos inaugurales de Henri Focillon y Jacques Maritain en el lanzamiento de la universidad en el exilio, RIEA anunció que "para establecer el intercambio con tan importante centro de alta cultura se ha constituido en Buenos Aires un Comité Argentino integrado por numerosas personalidades quienes patrocinarán la creación en la capital argentina de un Instituto Frances de Estudios Superiores" ${ }^{33}$ En un contexto de exilio, guerra y represión, la revista aspiraba a mantener vivo el vínculo con la intelectualidad francesa, vínculo que ya no era posible establecer a través de los mecanismos institucionales preexistentes para la cooperación científica y académica, de ahí que apareciera esbozada la idea de fundar un nuevo instituto. No disponemos de datos que corroboren la conformación de dicho comité ni hemos podido encontrar pruebas de que haya llegado a funcionar alguna vez; basta por el momento con poner de relieve la estrecha vinculación que tenía RIEA con este grupo de exiliados y lo comprometida que se hallaba en brindarle su apoyo a una institución que representaba lo más conspicuo de la intelectualidad francesa en el exilio a tal punto de pensar en la idea de fundar instituciones que consolidaran esa relación. En ese sentido, pues, decíamos más arriba que RIEA era la continuidad natural del Instituto de la Universidad de París de Buenos Aires y que es indisociable de esas redes académicas y de cooperación científica e intelectual.

La presencia de los exiliados franceses en Nueva York, que componían la "elite de la emigración francesa" de la guerra, según un historiador (Crémieux-Brilhac, 1996), fue de hecho constante en las páginas de RIEA, pero ello no iba en desmedro de trabar vínculos igualmente sólidos con franceses exiliados en otras latitudes como ocurrió, por ejemplo, con Georges Bernanos desde Brasil, cuya presencia fue asidua en la revista y que además trabó relación con la revista católica antifascista Orden Cristiano, de Buenos Aires. ${ }^{34}$ Las redes del exilio francés que construía RIEA eran pues continentales, vale decir, (pan)americanistas, aunque tampoco hay que pasar por alto que muchos de estos nombres se replicaban además en las diversas publicaciones y asociaciones antifascistas, así, por ejemplo, en Argentina libre (Bisso, 2009). Se ponía énfasis, de hecho, en que el exilio de los intelectuales franceses en América permitiría estrechar los contactos culturales a nivel continental. De igual modo, y en reciprocidad, se tendía a promover una creciente valoración por parte de los emigrados franceses en Nueva York hacia la construcción de sólidos vínculos con América Latina. En este sentido, cabe prestar atención a la figura del escritor Jules Romains, director del P.E.N. Club internacional, quien colaboró en la sección de literatura de la École des Hautes Études de Nueva York antes de exiliarse en México a partir de 1942, junto con Alfonso Reyes, quien le facilitó su instalación en el país, y el exiliado republicano Enrique Díez Canedo (Rolland, 2002). Romains fue, a la par de Bernanos desde Brasil, uno de los intelectuales franceses establecidos

33 Focillon, H., Maritain, J. y Cohen, G. (julio 1942). Victoria del espíritu. La Escuela Libre de Altos Estudios, RIEA, (6), pp. 515-517.

34 Bernanos, G. (febrero 1942). Nación contra raza, RIEA, pp. 40-44. 
en América Latina cuya voz encontraría mejor eco en Buenos Aires, ciudad que había visitado en ocasión del congreso de escritores de 1936 y donde tenía muchos contactos; los libros que publicó en el exilio, tanto en México como en los Estados Unidos a través de la Maison du livre français, eran reseñados de inmediato en RIEA, usualmente con comentarios muy favorables.

Una de sus intervenciones con más repercusión fue el discurso que dio en el Palacio de Bellas Artes de ciudad de México a fines de 1942, donde Romains sostuvo que los latinoamericanos tenían más empatía con la cultura francesa que los norteamericanos; en ese sentido, indicó que los pueblos latinoamericanos sintieron con mayor impacto la caída de París en 1940, en comparación con los países aliados y con Estados Unidos, donde, según denunciaba, no se le prestó mayor atención. Así, sostenía, el luto por Francia fue más duramente sentido allí donde más estrechos habían sido hasta allí los vínculos culturales. Tanto es así que en Estados Unidos se omitía mencionar a Francia entre los ganadores de la Primera Guerra Mundial -según denunciaba Romains- y se hablaba de la aceptación sin demasiada preocupación de la ocupación nazi del país en 1940 en un gesto que para Romains constituía una suerte de aceptación de la "dimisión” del papel de Francia en la cultura y la sociedad occidentales, cuya consecuencia fue que los Estados Unidos se vieron cada vez más presionados para ingresar como aliados en la Segunda Guerra Mundial.En ese sentido, según Romains, en Estados Unidos no abundaban las simpatías hacia Francia, mientras que en América Latina -enfatizaba- se podía percibir una valoración por el contrario todavía muy positiva de la cultura francesa -prueba viviente de ello, sin duda, era su amigo Alfonso Reyes- que le resultaba gratificante, en neto contraste con el mundo anglosajón. Además, Romains escribió descle el exilio un libro de impresiones acerca de las costumbres norteamericanas (Salsette découvre l'Amérique, Maison du livre français, 1942) donde trataría con escasa indulgencia el american way of life, libro que RIEA no reseñó, pero del que reprodujo un fragmento a modo de avance. ${ }^{35}$ Esto no significaba desconocer los errores cometidos por Francia en 1940, aclaraba, pero permitía reivindicar la necesidad de dejar en pie su misión, vale decir, su lugar como faro cultural que podría continuar ejerciendo, en especial sobre América Latina. Así, Romains invitaría a que América Latina se plegara del lado de los Aliados por solidaridad con la cultura francesa, antes que con los Estados Unidos y el panamericanismo:

La misión de Francia fue puesta en tela de juicio por la derrota militar de junio de 1940. Nos dicen -aun nuestros amigos- que esta vez la misión de Francia ha terminado. Que Francia ha renunciado a ella visiblemente, que ya no se trata de misión sino de dimisión [...] Empecemos por admitir que la Francia actual haya cometido los peores errores en su política exterior [...] Ello nada probaría contra el valor intrínseco de la cultura francesa [...] Aun cuando Francia como nación hubiera cometido desde hace 25 años innumerables errores, la cultura francesa y el genio francés, uno y otro seculares, no tendrían razón alguna de perder su lugar. ${ }^{36}$

35 Romains, J. (septiembre 1943). La mujer neoyorquina en la actualidad, RIEA, (20), pp. 95-101. 
Se trata de un discurso con el que los editores de RIEA se sentían a gusto, dada la centralidad que le adjudicaban a las letras francesas y a sus exiliados en la "república de las letras" que aspiraban a ver reconstruida entre Europa y las Américas, aunque esto no significa que RIEA se hubiera volcado a introducir una cuña entre los intelectuales franceses y el panamericanismo impulsado cada vez con más ímpetu desde los Estados Unidos -de hecho Leo Rowe, que presidía la Unión Panamericana, fue colaborador de la revista en alguna oportunidad ${ }^{37}$-, si bien de todas formas su principal aspiración era la revalorización de la cultura y las letras francesas. Los vínculos con Estados Unidos se fortalecieron a medida que avanzó la guerra, así, por ejemplo es de destacar que el excanciller José María Cantilo, que integraba el grupo editor de RIEA, impulsó un homenaje a Franklin D. Roosevelt que tuvo lugar en el Luna Park de Buenos Aires con el objeto de celebrar el ingreso de Estados Unidos en la guerra, que fue puntualmente reseñado en la revista ${ }^{38}$; por su parte, el médico Rafael Bullrich publicó un artículo exclusivo para RIEA en el que destacaría que Estados Unidos fue el país más comprometido en la tarea de brindar refugio a intelectuales y exiliados europeos (RIEA, 23, pp. 365-368). El corazón de los debates, sin embargo, giró en torno del modo en que los intelectuales franceses del exilio abordarían el llamado de Charles de Gaulle a participar de la Francia Libre.

\section{El debate entre Saint-Exupéry y Maritain y sus implicancias según RIEA}

La república de las letras del exilio francés en la que RIEA se movía con soltura no tardó en verse sacudida por discrepancias e incluso fuertes polémicas, si bien había algunos consensos básicos proporcionados por el compromiso con el antifascismo. El debate se desató entre Antoine de Saint-Exupéry y Jacques Maritain, dos nombres destacados en el exilio francés en Nueva York y, además, de constante presencia en RIEA. Entre 1942 y 1943, crecieron en Occidente las expectativas de un eventual triunfo aliado, porque en la campaña de África las fuerzas aliadas, incluso con apoyo de tropas de Francia Libre que se plegaron a la operación Torch bajo el liderazgo de Charles de Gaulle, habían logrado frenar al ejército nazi comandado por Rommel, lo cual fue muy movilizador para los intelectuales del exilio francés. Mientras se iniciaban los preparativos preparativos de la campaña africana, de Gaulle lanzó un llamado a la unidad a través diversas proclamas en las que apeló a la solidaridad de los franceses que ocupaban puestos en el aparato colonial francés en África del Norte, aun cuando esto implicaría llevar a las filas de la Francia Libre a quienes se hallaban sujetos, por sus funciones, a la autoridad de Vichy (De Gaulle, 1954). Si bien no parece haber sido muy eficaz el llamado a la unidad de los franceses de De Gaulle, puesto que no se podía pasar por alto que buena parte de los pieds noirs eran entusiastas del régimen de Vichy y no estaban dispuestos a cambiarse de bando, el tono conciliador de su discurso no tardó en suscitar debate (Gildea, 2015).

37 Rowe, L. (junio 1945). El acta de Chapultepec, RIEA, (40), pp. 280-282. Acerca de Rowe, Scarfi (2017).

38 S/a. (enero 1943). Significativo homenaje al presidente Roosevelt, RIEA, (12), p. 468. 
En este contexto debe ser situada la invocación de Antoine de Saint-Exupéry. El escritor tuvo varias intervenciones públicas donde no sólo abogó por redoblar el compromiso con la lucha contra el nazismo, cosa que lo llevaría a enrolarse como piloto al servicio de las tropas de De Gaulle, con quien había tenido diferencias, sino que, además, sostuvo la necesidad de atraer a la lucha contra el nazismo a todos los franceses. Su apelación se extendió a quienes se hallaban bajo el régimen de Vichy e incluso también los que se encontraran "como rehenes" bajo la ocupación alemana, una idea que difundió ampliamente y que se volvió polémica, porque suponía exculpar de responsabilidad a los franceses colaboracionistas, considerándolos meramente como víctimas involuntarias de las circunstancias, en una interpretación que llevaba a alimentar la tesis exculpatoria de que el régimen de Pétain era solamente un escudo protector para Francia frente al nazismo (Saint-Exupéry, 1968). ${ }^{39}$ Así, Saint-Exupéry desató una viva discusión que se agitó todavía más cuando, desde Nueva York, publicó una carta que tuvo mucho impacto y circulación en las comunidades francófilas a uno y otro lado del Atlántico. Su "carta a los franceses" de noviembre de 1942 llegaba en un momento clave de la Segunda Guerra Mundial cuando los Aliados estaban lanzándose a la campaña de África del Norte (la primera campaña ofensiva aliada en el Mediterráneo). Si bien la invocación de Saint-Exupéry, en cierto sentido, estuvo en línea con las proclamas conciliadoras del propio de Gaulle antes del desembarco en tierras africanas, el escritor dio un paso más osado todavía porque no solamente apeló a la unidad con vistas a la lucha (un llamado que podía ser justificado por la necesidad instrumental de evitar que los funcionarios de Vichy repelieran la invasión, tal como temían las tropas anglo-norteamericanas y, por el contrario, se plegaran al bando contrario), sino que además reivindicó la necesidad de una reconciliación entre los franceses que habían quedado de un lado y del otro del canal de la Mancha.

Así, la intervención de Saint-Exupéry dejó un sabor ambiguo porque no tenía la mirada condenatoria al régimen de Vichy y a la ocupación que sostenía buena parte del exilio francés en Nueva York (de hecho, desde junio de 1940 Saint-Exupéry consideró importante continuar publicando en Francia durante la guerra, cosa que habían decidido no hacer sus compañeros de exilio en Estados Unidos) y, a la par, no vacilaba en expresar su temor de que de Gaulle concentrara en sus manos demasiado poder y se volviera un autócrata una vez concluida la guerra, lo cual puso en evidencia que el exilio francés en Estados Unidos era menos homogéneo de lo que parecía a simple vista (Loyer, 1995; Schiff, 1993). La aparición de su carta bajo el lema " $D$ ' abord la France" ${ }^{40}$ fue de alto impacto (se publicó originalmente en Canadá, pero fue de inmediato traducida por el New York Times, donde apareció el 29 de noviembre de 1942), porque se trataba de un documento en el que Saint-Exupéry no solo apelaba a todos los franceses, en virtud de su patriotismo, a plegarse a la lucha contra el nazismo, sin importar de qué lado del Atlántico se encontraran y sin importar siquiera cuál había sido su actitud y conducta en junio de 1940 cuando se firmó el armisticio que sometió a Francia a

39 El texto fue reseñado en RIEA, 23 (diciembre 1943), pp. 343-346.

40 Francia ante todo (traducción propia). 
los nazis, sino que además, al abogar por la reconciliación, dejaba la puerta abierta a que los colaboracionistas pudieran quedar redimidos. El documento, finalmente, se publicó íntegro en RIEA en junio de 1943 traducido al español:

Franceses, reconciliémonos para servir.

Primero diré algunas palabras con el fin de tratar de purgarlos, sobre los litigios que han atormentado a los franceses. Porque ha habido un malestar francés. Un malestar grave. Muchos de nosotros que han sufrido desgarramientos de sus conciencias tienen necesidad de ser apaciguados. [...] ¿Para qué atascarse en los antiguos litigios? Conviene unir, no dividir; abrir los brazos y no excluir. ¿Valían nuestros litigios tales odios? [...] Todos estábamos de acuerdo sobre nuestra fe. Todos anhelábamos salvar a Francia. [...]

Tanto los unos como los otros condenábamos todo espíritu de colaboración entre Francia y Alemania, [...] Por consiguiente nuestro país estaba amenazado por la exterminación pura y simple, bajo apariencias legales y administrativas, de sus seis millones de hombres adultos. Francia sólo disponía de palos para oponerse a esta caza de esclavos. ¿Quién puede realmente juzgar lo que hubiera debido hacer su resistencia? [...] Abandonemos provisoriamente el rol de jueces a los historiadores y a las cortes marciales de la posguerra.

[...] No querellemos entre franceses en nombre de las precedencias, de los homenajes rendidos, de la justicia, de prioridades. No se nos ofrece nada de eso, se nos ofrecen fusiles. Los habrá para todo el mundo. [...] El conjunto al que me incorporo no es ni un partido político ni una secta: es mi país. Poco importa quién nos mandará [...] Anhelamos la movilización militar de los franceses de los Estados Unidos.

[...] ¡Ah! Franceses, bastaría para establecer la paz entre nosotros reducir nuestros disentimientos a sus verdaderas proporciones. [...] ¿Creen ustedes franceses que esas opiniones diversas sobre un gobierno caduco merecen que aún nos odiemos? [...] ¡Franceses, reconciliémonos! ${ }^{41}$

El llamado a la reconciliación a todos los franceses, acompañado de la exhortación a la lucha, no restañó las heridas sino que, por el contrario, despertó rápidas reacciones en la comunidad francesa del exilio neoyorquino. La réplica no tardó en llegar de la mano de Jacques Maritain, quien se apresuró a responder en un texto de fuerte impacto, bajo el elocuente título de "Parfois il faut juger" ("En ocasiones, es preciso juzgar"). En Buenos Aires, el texto circuló ampliamente en la comunidad francesa. Así, por ejemplo, se publicó en el periódico antifascista La France Nouvelle, de Buenos Aires, una publicación que muchas veces era citada o referenciada en RIEA. Maritain señaló que la invocación de Saint-Exupéry podría ser utilizada por muchos que aplaudieron en su hora la Francia de Vichy pero que, desencantados por las condiciones y las consecuencias de la ocupación nazi, y además preocupados por el modo en que el tablero de la guerra estaba cambiando con los avances aliados, podrían volcarse hacia la causa de la resistencia, de una manera que podía ser juzgada acomodaticia y puramente instrumental por parte de quienes habían condenado el armisticio de 1940 desde la primera hora. En sus palabras, era necesario señalar el riesgo de que el régimen de Vichy

41 de Saint-Exupéry, A. (junio 1943). Carta a los franceses, RIEA, (17), pp. 360-363; también puede verse Saint-Exupéry (1994). 
pudiera aprovechar la situación para intentar redimirse plegándose del lado de los Aliados porque, según Maritain, tal cosa era inadmisible y, en suma, era imperativo juzgar, en lugar de abogar por la reconciliación:

\begin{abstract}
Lamento estar en desacuerdo con un hombre al que estimo. La carta de SaintExupéry se presta a confusiones graves a las que es necesario responder. [...] hablo de aquellos que [...] han aceptado, incluso por un tiempo, la posibilidad de una Francia que desempeñe su papel en el concierto de una Europa alemana; estoy hablando de todos aquellos que han cubierto con su autoridad las leyes, la política, la propaganda y las represiones de Vichy. Estas personas pueden algún día intentar redimirse en el campo de batalla, como soldados, no como líderes políticos, si se pasan del lado de los Aliados o junto a la Francia Combatiente [...] Vichy no es Francia y no se puede confundir al pueblo francés con un poder usurpado que surge de la derrota y la vergüenza. [...] Saint-Exupéry no solo quiso abogar por Francia. Lo triste es que, contra sí mismo, parece defender a Vichy.
\end{abstract}

[Saint- Exupéry] Se dirige a todos los franceses para hablarles sobre lo que afecta el bien de nuestro país, pero no ve la necesidad de tener en cuenta los deseos de los franceses en este asunto de Estado de la "organización provisional de la Francia" [...] ¿Cómo se pretende que la cuestión del futuro gobierno de Francia no sea de importancia para los franceses? Desde junio de 1940, en verdad, no ha habido un gobierno francés. Hasta el momento en que el pueblo francés no pueda expresarse y decidir libremente sobre la nueva constitución de su república, no habrá un gobierno francés con poder legítimo [...]

Pero no nos pidan que transformemos nuestra lucha contra el enemigo [nazi] en una sumisión política a un pseudogobierno como Vichy, que se arroga el derecho de hablar como si se tratara de Francia. ${ }^{42}$

El trauma de Vichy no sólo afectaba a quienes habían sido partícipes de la ocupación nazi y serían luego de 1944 denunciados como colaboracionistas, más todavía si tuvieron ocasión de ocupar puestos de relieve en el aparato político o administrativo de Vichy, en el territorio francés o en sus colonias (Rousso, 1991; Rousso, 2010), sino también a quienes se encontraban en el exilio y se ubicaban en posiciones encontradas frente a la etapa decisiva en la lucha que se abría en 1943 en el marco de la Segunda Guerra Mundial, cuando todavía no se podía predecir el desenlace. El debate entre Saint-Exupéry y Maritain era en este sentido crucial para todo el exilio francés en las Américas, pero RIEA eludió la discusión en este punto: así, omitió publicar la réplica a la carta de Saint-Exupéry, aun cuando Maritain había ocupado un lugar central en sus páginas, incluso desde su primer número. El silencio de RIEA es tanto más elocuente puesto que no es posible imaginar que se la omitiera por puro desconocimiento; cabe pues postular como hipótesis que RIEA ignoró la polémica para tratar de mostrar un frente unido y sin fisuras entre los intelectuales franceses exiliados, algo similar a lo que hiciera, a su vez, la revista Sur, de Victoria Ocampo, entre cuyos interlocutores se contaban ambos partícipes en esta polémica (King, 1989). No olvidemos en este sentido el texto de Caillois publicado en el primer número de RIEA donde se apelaba a la conmiseración para con los intelectuales que habían quedado en

42 Maritain, J. (janvier 1943). Parfois il faut juger, La France Nouvelle, (14), pp. 3-4 (traducción de la autora). El texto fue reproducido íntegro, pero no estuvo acompañado de debate o discusión. 
territorio galo, un texto que enlazaba a ambas publicaciones que ahora una vez más volvían a encontrarse hermanadas en sus posicionamientos. Saint-Exupéry fue claro en su apelación a la solidaridad de los franceses libres para con los que seguían de "rehenes" en el continente, a la par que omitía mencionar cualquier solidaridad explícita con las iniciativas de los Aliados en la lucha contra el nazismo. Así, el debate no solo debe ser situado en la fractura entre el antifascismo y el fascismo, aún con sus grises, como se vio, sino que además permite llamar la atención del modo en que dicha polarización se vio desafiada e incluso tensionada por la invocación a la reconciliación nacional puesto que Saint-Exupéry dejó de lado cualquier apelación a la solidaridad antifascista transnacional y se focalizó en invocar la solidaridad nacional de los franceses con todos sus compatriotas. (Consistente con esa invocación, el escritor y piloto se plegó a las tropas gaullistas establecidas en Argelia en mayo de 1943 y falleció al año siguiente en un accidente de aviación.)

Más todavía, es harto llamativa la significativa demora en la publicación del texto de Saint-Exupéry, que llegó a las páginas de RIEA más de seis meses después de su publicación original y, por ende, sumamente descontextualizado. Para junio de 1943, ya había concluido la campaña de África del Norte y los Aliados se preparaban para su desembarco en la península italiana, de tal modo que la guerra se volcaría de lleno sobre Europa occidental; en este contexto, hablar de reconciliación cobraba un sentido mucho más fuerte que un semestre atrás, puesto que las perspectivas de un triunfo aliado comenzaban entonces a ser vislumbradas con más nitidez, reforzadas a su vez por el desenlace de Stalingrado. Una vez que la idea de reconciliación quedaba descontextualizada del momento de la campaña africana en el que había visto la luz y se trasladaba al estado de situación de mediados de 1943, esta vez en Europa, ya no podía ser leída como una simple apelación a la unidad puramente estratégica en medio de una arriesgada campaña militar (como hiciera de Gaulle en 1942). Por ello, resulta tanto más significativa y reveladora la omisión de la publicación de la réplica de Maritain por parte de RIEA, omisión que sólo puede ser comprendida, entonces, como una toma de posición explícita en ese debate hacia las palabras del escritor Saint-Exupéry. En efecto, el texto de Saint-Exupéry fue acompañado por el siguiente encabezado sin firma, redactado por los editores de RIEA: "Se agrega hoy un profundo sentimiento de admiración por la emocionante Lettre aux français [...] Saint-Exupéry es para sus compatriotas desamparados una guía en las tinieblas".43

Hubo que aguardar a la liberación de Francia del nazismo en agosto de 1944 para encontrar en RIEA una mención explícita de los gestos colaboracionistas de aquellos escritores e intelectuales que convivieron con el régimen de ocupación y, a su vez, una reivindicación neta de aquellos otros que se comprometieron y apoyaron abiertamente la resistencia, incluso a través de publicaciones clandestinas, entre estos últimos, Jean Paulhan, Jean Guehénno, François Mauriac, Louis Aragon, Julien Benda, Paul Valéry, Paul Éluard, Jean Paul Sartre, Albert Camus, Georges Duhamel, Paul Claudel. Así, después de la liberación, se denunció en 
RIEA a los colaboracionistas a través de la reproducción de una lista de nombres de los intelectuales sospechados que circuló en varios periódicos antifascistas de Buenos Aires (a su vez reproducida de Lettres françaises, homónima de la revista de Victoria Ocampo, pues se trataba de la revista fundada en la clandestinidad por Jean Paulhan). En esa lista se contaron Drieu la Rochelle (de larga amistad con Victoria Ocampo, como se sabe, y que ocupó el cargo de director de La Nouvelle Revue Francaise a partir de 1940), Alexis Carrel, Louis Céline, Robert Brasillach, Charles Maurras, entre otros. ${ }^{44}$ Algunos de ellos fueron juzgados y sufrieron condenas en la posguerra -el caso de Brasillach fue de todos ellos el más drástico puesto que fue fusilado, aun cuando François Mauriac hizo gestiones a su favor, en nombre de la pérdida que representaría para las letras francesas (Lottman, 1986: p. 138)-.Quedó así allanado el terreno para que Maritain recobrara sobre el final de la guerra un lugar de preeminencia en RIEA, pero luego de 1945 se trata de un Maritain más inocuo de todas maneras, volcado a reflexionar sobre las consecuencias de la liberación de Francia, luego de la caída de Pétain, la instalación del gobierno provisional en manos del general de Gaulle y el nuevo contexto de posguerra sobre el cual escribió: "la alegría exultante de la liberación que bien podía haberle hecho concebir la ilusión de que toda desventura había terminado, dio súbitamente paso a nuevas ansiedades y decepciones". ${ }^{45}$ No había dudas de que las heridas estaban abiertas. RIEA no eludió en este nuevo contexto la discusión en torno de la denuncia de funcionarios y figuras públicas del régimen de Vichy que fueron juzgados como colaboracionistas y en algunos casos terminaron ejecutados, decisión que la revista abordó con prudencia, sin omitir señalar que la consideraba excesiva en algunas ocasiones. ${ }^{46}$

En este contexto, desde el segundo semestre de 1945, RIEA perdió el pulso y el ritmo; pasó a publicar tiradas bimensuales y se concentró básicamente en reconstruir distintas aristas de la vida intelectual durante la resistencia francesa, aunque también publicaría un número de homenaje a Federico García Lorca, a diez años de su asesinato. ${ }^{47}$ Fue también en esa coyuntura cuando intentó abrir sus páginas a la escena literaria argentina y reflejar algunas de sus nóveles plumas: así, por ejemplo, se incluyó una colaboración del joven Julio Cortázar que correspondía a una presentación de Memorias de una enana del escritor británico Walter de la Mare que tradujo para editorial Nova. ${ }^{48}$ Cuando en plena posguerra renacía la vida cultural en Francia y comenzaba a publicarse cada vez más, no sólo por el regreso de muchos exiliados, sino por las nuevas generaciones que veían la luz luego de la liberación ("hoy [...] se publica mucho en Francia y en efecto no todo es de buena calidad"49), RIEA dejó de aparecer: con la posguerra en marcha, su misión en la "república de las letras" podía darse por concluida.

44 Lettres françaises, RIEA, 32-33 (septiembre-octubre 1944), pp. 382-385.

45 Maritain, J. (julio 1945). Aurora de grandeza, RIEA, (41), pp. 341-342.

46 En este sentido, Grosselin, A. (julio 1944). Misterios del colaboracionismo. P. Henriot, ministro de propaganda de Vichy, RIEA, (30), pp. 374-381.

47 Bergamín, J. (julio-agosto 1946). Muerte de Federico García Lorca, RIEA, (48), p. 375.

48 Cortázar, J. (julio-agosto 1946). Walter de la Mare. Mediador entre dos mundos, RIEA, (48).

49 Bastide, R. (julio-agosto 1946). La época del silencio y la de la palabra, RIEA, (48), pp. 432-433. 


\section{Conclusiones}

Hemos tratado de situar RIEA en la encrucijada de varios campos y líneas de investigación: en primer lugar, en la historia de las revistas culturales y literarias, aunque con un formato específico centrado más en el digest que en las revistas de mayor porte e influencia. Por otro lado, en la historia del antifascismo, en especial, del gaullismo en la Argentina, donde descollaron distintas organizaciones tanto de intelectuales como de políticos y activistas frente a las cuales, nuevamente, RIEA quedó en un muy discreto segundo plano. Luego, también es importante el abordaje de las redes con y entre exiliados en escala transnacional, donde hemos visto cómo se solapaban exiliados republicanos españoles con italianos, austriacos y otros, entre los cuales los franceses ocuparon sin duda el primer puesto en RIEA. Aunque en este aspecto también se podrá argüir que esta revista no ocupó un importante renglón, puesto que no fue capaz de articular gestiones que trajeran al Río de la Plata a intelectuales franceses del exilio, a pesar de que esas redes de cooperación intelectual habían sido constituidas con dos décadas de anterioridad a través del Instituto de la Universidad de París fundado y dirigido por Adolfo Bioy, instituto que no logró convertirse en una base suficiente como para establecer en la Argentina un sucedáneo de la universidad francesa en el exilio que sí tuvo, por contraste, Nueva York.

Ahora bien, a pesar de su marginalidad relativa, de su falta de visibilidad en la escena literaria e intelectual en la Argentina (el grueso de sus colaboradores e interlocutores fueron extranjeros) y a pesar de la recepción parcial que hizo del debate entre Saint-Exupéry y Maritain, quizás el principal debate dentro del exilio francés en las Américas, el modo en que RIEA optó por omitir la voz de Maritain, sumiéndolo en un silencio que resulta tanto más significativo puesto que no podía ignorarlo, hace que valga la pena detenernos en ella. Porque su adhesión al pedido de Saint-Exupéry por la reconciliación entre los franceses del exilio antifascista -por cierto, sin hacer mención de los comunistas-, con los franceses que permanecieron bajo el régimen de Vichy en nombre de la identidad nacional compartida, no fue sólo tácita. Que una voz respetada, influyente y hasta entonces muy cercana de RIEA como la de Maritain se levantara para rechazar esa invocación y en la revista se optara por no publicarlo, nos devuelve al problema señalado en reiteradas ocasiones por los estudiosos del antifascismo acerca de las diferentes vertientes que convivieron en su seno y que, por momentos, podían llevar a disolver cualquier aspiración a constituir un frente común puesto que allí podían confluir liberales, católicos, reformistas, republicanos, conservadores, socialistas, comunistas, del partido radical, entre otros, diferencias que se volvieron tanto más resonantes conforme la guerra se decantó a favor de los Aliados y se abrió el paso al proceso de "depuración" de los colaboracionistas. Así, mientras la elite intelectual de la resistencia pasó a ocupar puestos relevantes en las instituciones culturales de la Francia de posguerra, RIEA dejaba de existir. 


\section{Q Bibliografía}

" Aron, R. (1954). Histoire de Vichy 1940-1944. París: Fayard.

" Beigel, F. (2006). La epopeya de una generación y una revista. Las redes editoriales de José Carlos Mariátegui en América Latina. Buenos Aires: Biblos.

" Bertúa, P. (2015). "Si me quieres escribir...". Mujeres en la prensa cultural antifascista (Argentina, 1930-1940). Arenal, 22 (1), pp. 5-30.

"Bisso, A. (2016). "The Argentine Antifascist Movement and the Building of a Tempting Domestic Appeal, 1922-46". En García, H., Yusta, M., Tabet, X. y Clímaco, C. (eds.). Rethinking Antifascism. History, Memory and Politics, 1922 to the present (pp. 133-151). New York: Berghan Books.

"Bisso, A. (2005). Acción Argentina. Un antifascismo nacional en tiempos de guerra mundial. Buenos Aires: Prometeo.

"Bisso, A. (ed.) (2007). El antifascismo argentino. Buenos Aires: Cedinci.

"Bisso, A. (2009). Argentina libre y Antinazi: dos revistas en torno de una propuesta político-cultural sobre el antifascismo argentino 1940-1946. Temas de Nuestra América. Revista de estudios latinoamericanos, 25(47), 63-84

" Bisso, A. (2019). "La revista Unidad. Un cruce entre intelectualidad y antifascismo", en AMÉRICALEE. El portal de publicaciones latinoamericanas del siglo XX. ISSN: 2545-823X. Disponible en: www.americalee.cedinci.org

" Buchbinder, P. (2017). Redes académicas transnacionales: Argentina a principios del siglo XX. Cuadernos Americanos, 159, pp. 125-150.

" Burrin, P. (1995). France under the Germans. Collaboration and Compromise. New York: The New Press.

"Cane, J. (1997). Unity for the Defense of Culture: The AIAPE and the Cultural Politics of Argentine Antifascism, 1935-1943. The Hispanic American Historical Review, 77 (3), pp. 443-482.

"Celentano, A. (2006). Ideas e intelectuales en la formación de una red sudamericana antifascista. Literatura y lingüística, 17, pp. 195-218.

" Chaubet, F. et Loyer, E. (2000). L’École Libre des Hautes Études de New York: exil et résistance intellectuelle (1942-1946). Revue Historique, 302, 4 (616), pp. 939-972.

"Crémieux-Brilhac, J. L. (1996). La France Libre. De l'appel du 18 juin à la Libération. Paris: Gallimard.

"Devés, M. (2016). Teatro de vanguardia y revistas culturales de izquierda en el Buenos Aires de los años veinte. Revista de literaturas modernas, 46 (1), pp. 43-66.

"Devés, M. (2016-2017). Arte y antifascismo en la revista Monde 1928-1935. Políticas de la memoria, 17, pp. 135-147.

"Friedmann, G. (2010). Alemanes antinazis en la Argentina. Buenos Aires: Siglo XXI.

" García, H., Yusta, M., Tabet, X. y Clímaco, C. (eds.). Rethinking Antifascism. History, Memory and Politics, 1922 to the present. New York: Berghan Books.

" Gildea, R. (2015). Fighters in the shadows. A new history of the French resistance. Massachusetts: The Belknap Press of Harvard University Press. 
" Goetschel, P. et Loyer, E. (2011). Histoire culturelle de la France, de la belle époque à nos jours. Paris: Colin.

" Granados, A. y Rivera Mir, S. (Coords.) (2018). Prácticas editoriales y cultura impresa entre los intelectuales latinoamericanos en el siglo XX. México: El Colegio MexiquenseUAM Cuajimalpa.

" Guzmán, D. (2011). El antifascismo en Santiago del Estero: La Brasa, 1935-195. Cifra, 6, pp. 11-25.

" Jorge Penado, D. (2015). Haciéndose los sordos en Ginebra. La Sociedad de Naciones y la guerra de España. Madrid: Universidad Complutense, tesis doctoral.

"King, J. (1989). Sur. Estudios de la revista argentina y de su papel en el desarrollo de una cultura 1931-1970. México: Fondo de Cultura Económica.

"Krohn, C. D. (2019). Refugee Scholars and the New School for Social Research in New York After 1933: Intellectual Transfer and Impact. En Pries, L. y Yankelevich, P. (eds.). Europe and Latin American Social Scientists as Refugés, Emigrés and Return-Migrants. New York: Palgrave Macmillan.

" Krohn, C. D. (1993). Intellectuals in Exile. Refugee Scholars and the New School for Social Research. Massachusetts: University of Massachusetts Press.

" Lafleur, H., Provenzano, S. y Alonso, F. (2006) Las revistas literarias argentinas 1893-1967. Buenos Aires: El 8vo. loco.

" Lida, M. (2013). Monseñor De Andrea. Obispo y hombre de mundo. Buenos Aires: Edhasa.

" Lida, M. (2015). “Estética, cultura y política en la revista Criterio (Argentina, 1928-1936)", Nuevo Mundo Mundos Nuevos, consultado en línea el 15/6/2020 en http://journals. openedition.org/nuevomundo/67968

" Losada, L. (2016). Marcelo T. de Alvear. Revolucionario, presidente y líder republicano. Buenos Aires: Edhasa.

" Losada, L. (2019). Maquiavelo en Argentina. Usos y lecturas, 1830-1940. Buenos Aires: Katz.

" Lottman, H. (1986). The Purge. The Purification of French Collaborators after Second World War. New York: Morrow and Company.

" Loyer, P. (1995). France under the Germans. Collaboration and Compromise. New York: The New Press.

" Marín, M. A. (1964). Isidro Fabela. Foro Internacional. México, vol. V, 2 (18), pp. 151-182.

" Mauro, D. (2017). Católicos antifascistas en Argentina (1936-1943). Luigi Sturzo y las tramas locales de People \& Freedom Group. Itinerantes, 7, pp. 9-31.

" McQuade, F. (1992). Mundo nuevo: la nueva novela y la guerra fría cultural. América. Cahiers du CRICCAL, 9-10 (1992), pp. 17-26.

" Otero, H. (2012) Historia de los franceses en la Argentina. Buenos Aires: Biblos, 2012.

" Pasolini, R. (2013). Los marxistas liberales. Antifascismo y cultura comunista en la Argentina del siglo XX. Buenos Aires: Edhasa.

"Pasolini, R. (2005). El nacimiento de una sensibilidad política. Cultura antifascista, comunismo y nación en la Argentina: Entre la AIAPE y el Congreso Argentino de la Cultura, 1935-1955. Desarrollo Económico, 45 (179), pp. 403-433.

" Pasolini, R. (2006). La internacional del espíritu. La cultura antifascista y las redes de solidaridad intelectual en la Argentina de los años treinta. En García Sebastiani, M. Fascismo y antifascismo. Peronismo y antiperonismo. Conflictos políticos e ideológicos en 
la Argentina. Buenos Aires: Iberoamericana.

" Pasternac, N. (2002). Sur. Una revista en la tormenta 1931-1944. Buenos Aires: Paradiso Ediciones.

" Paxton, R. (1972). Vichy France, Old Guard and New Order 1940-1944. New York: Alfred Knopf.

"Peirano Basso, L. (2001). Marcha de Montevideo y la formación de la conciencia latinoamericana a través de sus cuadernos. Buenos Aires: Javier Vergara editor.

"Pelosi, H. C. (1999). Argentinos en Francia. Franceses en Argentina, una historia colectiva. Buenos Aires: Ciudad Argentina.

"Petra, A. (2017). Intelectuales y cultura comunista. Itinerarios, problemas y debates en la Argentina de posguerra. Buenos Aires: Fondo de Cultura Económica.

" Pita González, A. (2016). Redes transnacionales en América Latina durante la entreguerra. México: Universidad de Colima.

" Reggiani, A. (2010). "Vichy y los historiadores". En Reggiani, A. (ed.). Los años sombríos. Francia en la era del fascismo. Buenos Aires: Miño y Dávila.

"Rolland, D. (1995). Conflicto y crisis de representaciones: ¿la Segunda Guerra Mundial: ordalías del modelo francés en América Latina? Estudios Interdisciplinarios De América Latina Y el Caribe, 6 (1).

" Rolland, D. (2002). El exilio francés en México durante la Segunda Guerra Mundial. En Yankelevich, P. (ed.), México, país refugio. México: INAH.

" Rousso, H. (1991). The Vichy Sindrome. History and Memory in France since 1944. Massachusetts: Harvard University Press.

" Rousso, H. (2010). La trayectoria de un historiador del tiempo presente. En Reggiani, A. (comp.). Los años sombríos. Francia en la era del fascismo (1934-1944). Buenos Aires: Miño y Dávila.

"Saítta, S. (2005). “Polémicas ideológicas, debates literarios en Contra. La revista de los franco-tiradores". En Contra. La revista de los franco-tiradores. Bernal: Universidad Nacional de Quilmes.

" Saint- Exupéry, A. de (1968). Carta a un rehén, Buenos Aires: Goncourt.

" Saint-Exupéry, A. de (1994). D’abord la France. Écrits de Guerre 1939-1944. Paris: Gallimard Folio.

"Scarfi, J. P. (2017). The Hidden History of International Law in the Americas. Empire and Legal Networks. New York: Oxford University Press.

"Schiff, S. (1993). Saint- Exupéry. A biography. New York: Alfred Knopf.

"Seidman, M. (2017). Antifascismos, 1936-1945. La lucha contra el fascismo en ambos lados del Atlántico. Madrid: Alianza Editorial.

" Ubelaker Andrade, L. (2019). Connected in print: Selecciones del Reader's Digest, U.S. cultural relations, and the construction of a global middle class. Palabra Clave, 22(4). DOI: doi.org/10.5294/pacla.2019.22.4.7

"Vicente, M. (2015). La cuestión del liberalismo en Orden Cristiano: entre las posiciones antifascistas y la problemática identitaria (1941-1948). Pasado Abierto, 2, pp. 242-264.

"Zanca, J. (2013). Cristianos antifascistas. Conflictos en la cultura católica argentina. Buenos Aires: Siglo XXI. 